\title{
Desain Visual Los Dawet Telasih dan Lenjongan Pasar Gede Hardjonagoro menggunakan Evaluasi Visual Kansei
}

\author{
Mei Andrianto ${ }^{1)}$, Muhammad Ridwan Andi Purnomo ${ }^{2)}$ \\ Magister Teknik Industri, Fakultas Teknik Industri, Universitas Islam Indonesia \\ Jl. Kaliurang Km. 14,5 Yogyakarta, 55584, Indonesia \\ e-mail:16916110@ students.uii.ac.id ${ }^{1)}$ \\ E-mail : ridwan_ie@uii.ac.id ${ }^{2)}$
}

\begin{abstract}
ABSTRAK
Kecenderungan penurunan jumlah pengunjung kurun waktu lima tahun terakhir di Pasar Gede Hardjonagoro sangat mempengaruhi pendapatan pendagang. Namun penurunan kunjungan konsumen tidak dirasakan oleh pedagang jajanan pasar dan oleh-oleh khas Surakarta, hal ini disebabkan adanya peningkatan kunjungan konsumen luar kota yang berwisata ke Kota Surakarta. Inovasi desain visual los dawet telasih dan los lenjongan dipilih dalam penelitian karena dua obyek tersebut menjadi daya tarik utama bagi wisatawan ke Pasar Gede Hardjonagoro. Namun berdasarkan persepsi konsumen, desain los dawet telasih dan los lenjongan kurang menarik sehingga diperlukan rekayasa desain untuk meningkatkan daya tarik kunjungan pembeli. Tahapan proses penelitiannya dengan menggali emosi dan perasaan konsumen terhadap situasi riil yang ada. Hasil persepsi konsumen disintesakan ke dalam elemen-elemen desain dan disurveykan ke dalam bentuk pilihan konsep desain. Elemen-elemen desain digabungkan dalam bentuk desain awal yang akan disurveykan kembali dan dikonsultasikan dengan pihak terkait. Hasil dari penelitian adalah konsep desain akhir secara visual beserta elemen-elemen desain penyusunnya.
\end{abstract}

Kata kunci : desain visual kansei, desain los pasar, kansei engineering,

\section{Visual Design of Dawet Telasih and Lenjongan Stalls at Gede Hardjonagoro Market using Kansei Visual Evaluation}

\begin{abstract}
The downward trend in the number of visitors in the past five years at Gede Hardjonagoro Market greatly affects the income of traders. However, the decrease in consumer visits is not felt by market hawkers and souvenirs of Surakarta. This is due to an increase in out-of-town consumer visits to Surakarta. The visual design innovation of dawet telasih and lenjongan stalls was chosen in the study because these two objects become the main attraction for tourists to the Gede Hardjonagoro Market. However, based on consumer perception, the design of the dawet telasih and lenjongan stalls is less attractive so that design engineering is needed to increase the attractiveness of consumer visits. The stages of the research process were by exploring the emotions and feelings of consumers towards the real situation that exists. The results of consumer perceptions were synthesized into the design elements and surveyed in the form of a choice of design concepts. The design elements were combined in the form of initial designs which will be surveyed again and consulted with relevant parties. The results of the study are the visual design concept and its constituent design elements.
\end{abstract}

Keywords: kansei engineering, kansei visual design, market stall design

\section{Pendahuluan}

Tidak dapat dipungkiri perkembangan teknologi digital saat ini telah membawa perubahan kebiasaan dari masyarakat. Dahulu internet dan perangkat digital seperti komputer dan telepon pintar (smartphone) bukanlah barang primer yang keberadaannya harus ada, namun sejalan dengan 
perkembangan teknologi kebutuhan akan informasi dan komunikasi yang cepat merupakan hal pokok yang sangat dibutuhkan masyarakat di era saat ini. Demikian pula dalam rangka memenuhi kebutuhan akan barang dan atau jasa, dengan adanya perkembangan teknologi informasi saat ini hal tersebut tidaklah sulit lagi. Hanya dengan ujung jari segala keperluan barang kebutuhan dapat dibeli melalui daring. Hal inilah yang dikawatirkan sebagian pelaku usaha retail dengan adanya perubahan pola belanja masyarakat yang bergeser sebagai akibat semakin maraknya perdagangan secara daring. Fenomena lain dari perubahan perilaku masyarakat era digital yaitu perilaku membagikan aktifitas atau kegiatan yang sedang dijalaninya sebagai bagian dari gaya hidup berbagi informasi. Aktifitas yang dibagikan dapat berupa foto atau video ke media sosial yang diikuti (Sulistyaningtyas et al., 2012).

Perubahan perilaku masyarakat dalam belanja kebutuhan sehari-hari juga terjadi di Pasar Gede Hardjonagoro Kota Surakarta atau yang lebih dikenal dengan sebutan Pasar Gede. Berdasarkan informasi melalui wawancara secara acak terhadap pedagang di Pasar Gede didapatkan tren pengunjung dalam kurun waktu lima tahun terakhir mengalami penurunan. Sebanyak $90 \%$ responden pedagang mengatakan penurunan jumlah pengunjung, sedangkan responden $10 \%$ menyatakan mengalami kenaikan pengunjung. Pedagang yang menyatakan adanya kenaikan pengunjung adalah di area jajanan pasar, hal ini disebabkan jumlah wisatawan luar kota yang semakin banyak berkunjung ke Kota Surakarta utamanya ke Pasar Gede.

Informasi awal tentang daya tarik wisata Pasar Gede selanjutnya dilakukan penelitian lanjutan untuk mengetahui spot atau area jenis dagangan yang paling banyak dipersepsikan oleh konsumen. Hasil survey dapat digambarkan dalam Gambar 1 :
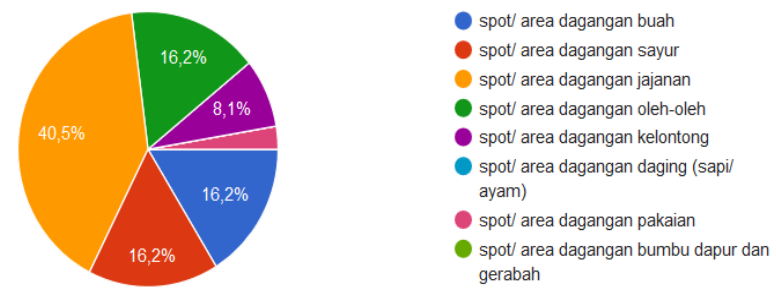

Gambar 1. Prosentase Persepsi Konsumen

Terhadap Area Dagangan Yang Paling Menarik Minat Konsumen

Dalam Gambar 1 dijelaskan area dagangan yang paling menarik menurut konsumen adalah area dagangan jajanan pasar. Area jajanan pasar diminati oleh konsumen sebesar 40,5\%, hal ini membuktikan bahwa spot dagangan jajan menjadi tujuan tertinggi bagi konsumen yang berkunjung ke Pasar Gede. Berdasarkan informasi pengelola pasar dan konsumen, jenis jajanan pasar yang paling diminati pengunjung terutama wisatawan luar kota adalah dawet telasih dan lenjongan.

Namun berdasarkan persepsi konsumen, desain los dawet telasih dan los lenjongan kurang menarik sehingga diperlukan rekayasa desain untuk meningkatkan daya tarik kunjungan pembeli. Strategi bisnis yang diusulkan adalah dengan melakukan desain ulang los dagangan dawet telasih dan los lenjongan agar lebih menarik secara visual menurut persepsi konsumen.

(Ramachandiran \& Jomhari, 2015) dalam penelitiannya memvisualkan agen pendidik virtual yang berpengaruh pada emosi peserta didik. (Kobayashi et al., 2019) menggunakan pendekatan Kansei dan estetika elemen desain untuk perancangan desain kursi kantor, (Kagitani et al., 2015) dalam penelitiannya tentang rekayasa obyek gambar berdasarkan kata-kata Kansei menyimpulkan bahwa rekayasa visual dapat memberikan pengaruh terhadap emosi. (Mamaghani \& Mostowfi, 2016) dalam penelitiannya menjelaskan tentang eksplorasi penerapan rekayasa Kansei dalam penggalian emosional desain model taman. Dalam penelitian (Shaari, 2016) menggunakan metode Kansei Image Evaluation untuk menggali emosi dalam perancangan desain pakaian. (Rosen et 
al., 2016) memodelkan hubungan antara harapan dan persepsi pelanggan terhadap sifat permukaan produk. (Haddadian, 2016) menggunakan metode penilaian visual berbasis Kansei terhadap penataan furniture jalan di Kota Tabriz. Dalam penelitiannya (Y.H. Lin et al., 2017) mengabstraksi elemen budaya artistik Aborigin Taiwan untuk pengembangan produk baru. (Hapsari et al., 2017) dalam penelitiannya menggunakan metode Kansei Tipe I untuk merancang desain kursi penumpang pada kereta api (Arsovski et al., 2017) merancang produk peralatan rumah tangga berdasarkan analisa emosional pengguna. Dalam penelitiannya (C. C. Lin et al., 2017) menggunakan pendekatan Kansei Form Composition (KFC) untuk mengekstrak ikon Kota Kaohsiung untuk perancangan produk. (Kurochka et al., 2017) menggunakan analisa gambar pakaian yang dievaluasi dengan metode Kansei untuk mendapatkan desain yang paling diminati konsumen. (CHENG et al., 2017) menggunakan elemenelemen semantik dalam perancangan desain simbol. (Urquhart \& Wodehouse, 2017) dalam penelitiannya menyajikan kualifikasi dari estetika pola gambar untuk perancangan desain produk. (W. Wang et al., 2017) menggunakan analisa visual untuk mengembangkan ide kreatif budaya Saline Soil dalam perancangan produk rumah tangga. Dalam penelitian (M. F. Wang \& Hsiao, 2018) menggambarkan desain interior berbasis kata Kansei dengan pemilihan desain elemen dan gambar desain tiga dimensi. (Hsiao \& Chen, 2018) dalam penelitiannya menggunakan analisa Kansei untuk mengeksplorasi persepktif pelanggan terhadap lokasi restoran. (Quan et al., 2018) menggabungkan teknik Kansei dan pembelajaran mendalam untuk inovasi produk yang mentransfer warna dan pola ke dalam gambar. Dalam penelitian (Xiong et al., 2018) mengukur persepsi pelanggan tentang fitur produk pemanggang roti. (Yoshida et al., 2018) menerapkan metode Kansei Engineering untuk memahami emosi pengguna dalam penyusunan konsep awal desain arsitektur. (Soikun et al., 2019) menggunakan pendekatan Kansei untuk menggambarkan visualisasi tokoh animasi dengan berbagai ekspresi wajah. (Shao et al., 2019) menggunakan evaluasi Kansei untuk menggali sudut pandang kreatif dari renovasi bangunan lama. (Hadiana et al., 2019) dalam penelitiannya menterjemahkan perasaan emosional pengguna dalam komponen desain antar muka aplikasi perangkat lunak. (Wei, 2019) menerapkan metode Kansei untuk membangun model formatif Kansei ke dalam elemen formatif desain. (Ren et al., 2019) menerapkan Kansei Engineering untuk merancang desain dasboard mobil yang nyaman. (Y. Lin, 2019) meneliti tentang kecocokan visual warna untuk desain produk dengan metode Kansei Engineering Support System (KESS).

Tabel 1. Ringkasan Penelitian Kansei Sebelumnya

\begin{tabular}{|c|c|c|c|}
\hline Penulis & Obyek & Alat & Teknik \\
\hline $\begin{array}{l}\text { Ramachandiran } \\
\text { \& Jomhari, } 2015\end{array}$ & $\begin{array}{c}\text { Program } \\
\text { virtual }\end{array}$ & $\begin{array}{l}\text { Interaksi } \\
\text { manusia- } \\
\text { komputer }\end{array}$ & $\begin{array}{l}18 \text { sampel } \\
\text { agen } \\
\text { pendidik } \\
\text { virtual }\end{array}$ \\
\hline $\begin{array}{c}\text { Kobayashi, } \\
\text { Kinumura, \& } \\
\text { Higashi, } 2015\end{array}$ & Kursi kantor & $\begin{array}{c}\text { Desain } \\
\text { model tiga } \\
\text { level }\end{array}$ & $\begin{array}{c}4 \text { desain } \\
\text { kursi pilihan }\end{array}$ \\
\hline $\begin{array}{c}\text { Kagitani, et al., } \\
2015\end{array}$ & Foto & $\begin{array}{c}\text { Manipulasi } \\
\text { gambar }\end{array}$ & $\begin{array}{l}16 \text { sampel } \\
\text { modifikasi } \\
\text { foto }\end{array}$ \\
\hline $\begin{array}{l}\text { Mamaghani \& } \\
\text { Mostowfi, } 2016\end{array}$ & Taman kota & EEG, EMG & $\begin{array}{l}4 \text { sampel } \\
\text { taman }\end{array}$ \\
\hline Shaari N. , 2016 & Pakaian & $\begin{array}{c}\text { Kansei Image } \\
\text { Evaluation }\end{array}$ & $\begin{array}{l}9 \text { atribut } \\
\text { evaluasi }\end{array}$ \\
\hline $\begin{array}{l}\text { Rosen, Eriksson, } \\
\text { \& Bergman, } \\
2016\end{array}$ & $\begin{array}{c}\text { Material } \\
\text { rumah sakit }\end{array}$ & $\begin{array}{l}\text { Visualisasi } \\
\text { kata Kansei }\end{array}$ & $\begin{array}{l}13 \text { atribut } \\
\text { evaluasi }\end{array}$ \\
\hline Haddadian, 2016 & $\begin{array}{l}\text { Furnitur } \\
\text { taman }\end{array}$ & $\begin{array}{l}\text { Penilaian } \\
\text { visual }\end{array}$ & $\begin{array}{c}4 \text { sampel } \\
\text { desain } \\
\text { pemasangan }\end{array}$ \\
\hline $\begin{array}{c}\text { Lin, Pan, \& Lin, } \\
2017\end{array}$ & Pot gerabah & $\begin{array}{c}\text { Analisa } \\
\text { elemen } \\
\text { karakteristik }\end{array}$ & $\begin{array}{c}4 \text { desain pot } \\
\text { gerabah }\end{array}$ \\
\hline $\begin{array}{c}\text { Hapsari, } \\
\text { Sjafrizal, \& } \\
\text { Anugraha, } 2017\end{array}$ & $\begin{array}{c}\text { Kursi } \\
\text { penumpang } \\
\text { kereta api }\end{array}$ & KE tipe I & $\begin{array}{c}19 \text { fitur } \\
\text { semantic }\end{array}$ \\
\hline $\begin{array}{c}\text { Ivanovic, } \\
\text { Marcovic, } \\
\text { Arsovski, } \\
\text { Rackov, \& } \\
\text { Kuzmanovic, } \\
2017\end{array}$ & $\begin{array}{l}\text { Peralatan } \\
\text { rumah } \\
\text { tangga }\end{array}$ & $\begin{array}{l}\text { KE, Sensory } \\
\text { Emotional } \\
\text { Synergy, } \\
\text { Product } \\
\text { Design } \\
\text { Engineering }\end{array}$ & $\begin{array}{c}7 \text { desain unik } \\
\text { alat rumah } \\
\text { tangga }\end{array}$ \\
\hline $\begin{array}{c}\text { Lin, Tsai, \& Yu, } \\
2017\end{array}$ & $\begin{array}{l}\text { Alat rumah } \\
\text { tangga }\end{array}$ & $\begin{array}{l}\text { Kansei Form } \\
\text { Composition }\end{array}$ & $\begin{array}{l}7 \text { ikon Kota } \\
\text { Kaohsiung }\end{array}$ \\
\hline
\end{tabular}




\begin{tabular}{|c|c|c|c|}
\hline $\begin{array}{c}\text { Kurochka, } \\
\text { Sviruk, } \\
\text { Kuleshova, \& } \\
\text { Zakharkevich, } \\
2017\end{array}$ & Pakaian & $\begin{array}{l}\text { Analisa } \\
\text { gambar } \\
\text { Kansei }\end{array}$ & $\begin{array}{c}14 \text { fitur } \\
\text { semantic }\end{array}$ \\
\hline $\begin{array}{c}\text { Cheng, Lin, \& } \\
\text { Yang, } 2017\end{array}$ & Simbol & $\begin{array}{c}\text { Multi- } \\
\text { dimensional } \\
\text { Form Elemen } \\
\text { KE }\end{array}$ & $\begin{array}{l}4 \text { dimensi } \\
\text { semantic }\end{array}$ \\
\hline $\begin{array}{c}\text { Urquhart, } \\
\text { Robert, } \\
\text { Wodehouse, \& } \\
\text { Andrew, } 2017\end{array}$ & $\begin{array}{c}\text { Pola gambar } \\
\text { (pattern) }\end{array}$ & $\begin{array}{l}\text { Analysisng } \\
\text { emotive and } \\
\text { semantic }\end{array}$ & $\begin{array}{l}16 \text { pola } \\
\text { gambar }\end{array}$ \\
\hline $\begin{array}{c}\text { Wang, Liu, Ab } \\
\text { Karim, \& Mohd } \\
\text { Amran, } 2017\end{array}$ & Alat dapur & $\begin{array}{c}\text { Eye } \\
\text { movement } \\
\text { test }\end{array}$ & $\begin{array}{c}\text { Elemen } \\
\text { evaluasi } \\
\text { bertingkat }\end{array}$ \\
\hline $\begin{array}{c}\text { Wang \& Hsia, } \\
2018\end{array}$ & $\begin{array}{l}\text { Desain } \\
\text { interior }\end{array}$ & $\begin{array}{c}\text { KE } \\
\text { Evaluation, } \\
\text { Fussy, CAD }\end{array}$ & $\begin{array}{c}\text { Elemen } \\
\text { penyusun } \\
\text { desain 3D }\end{array}$ \\
\hline $\begin{array}{c}\text { Hsiao \& Chen, } \\
2018\end{array}$ & Restoran & $\mathrm{KE}$ & $\begin{array}{l}\text { Analisa } \\
\text { lokasi } \\
\text { restoran }\end{array}$ \\
\hline $\begin{array}{c}\text { Quan, } \mathrm{Li}, \& \mathrm{Hu}, \\
2018\end{array}$ & $\begin{array}{l}\text { Pola potong } \\
\text { pakaian }\end{array}$ & $\begin{array}{l}\text { KE base } \\
\text { neural style } \\
\text { for product } \\
\text { innovative }\end{array}$ & $\begin{array}{c}4 \text { sampel } \\
\text { pola potong }\end{array}$ \\
\hline $\begin{array}{c}\text { Xiong, Liu, } \\
\text { Weng, \& Liu, } \\
2018\end{array}$ & $\begin{array}{c}\text { Mesin } \\
\text { pemanggang } \\
\text { roti }\end{array}$ & $\begin{array}{l}\text { KE, Extract } \\
\text { product } \\
\text { feature }\end{array}$ & $\begin{array}{l}15 \text { gambar } \\
\text { sampel } \\
\text { produk }\end{array}$ \\
\hline $\begin{array}{c}\text { Yoshida A, } \\
\text { Maekawa, } \\
\text { Tsuchida B, \& } \\
\text { Nagaia, } 2018\end{array}$ & $\begin{array}{c}\text { Desain } \\
\text { arsitektur }\end{array}$ & EGM, PAC & $\begin{array}{l}\text { Observasi } 50 \\
\text { foto }\end{array}$ \\
\hline $\begin{array}{c}\text { Soikun \& } \\
\text { Ibrahim, } 2019\end{array}$ & $\begin{array}{c}\text { Tokoh } \\
\text { animasi }\end{array}$ & $\begin{array}{l}\text { VIW, } \\
\text { ACDAP }\end{array}$ & $\begin{array}{c}8 \text { elemen } \\
\text { desain }\end{array}$ \\
\hline $\begin{array}{l}\text { Shao, Nagai, \& } \\
\text { Sosa, } 2019\end{array}$ & $\begin{array}{l}\text { Bangunan } \\
\text { tua }\end{array}$ & $\begin{array}{c}\mathrm{KE} \\
\text { Evaluation }\end{array}$ & $\begin{array}{l}18 \text { gambar } \\
\text { sampel } \\
\text { gedung }\end{array}$ \\
\hline $\begin{array}{c}\text { Hadiana, } \\
\text { Permana, \& } \\
\text { Tjahjadi, } 2019\end{array}$ & $\begin{array}{l}\text { Aplikasi } \\
\text { Helpdesk }\end{array}$ & KE tipe I & $\begin{array}{l}5 \text { spesimen } \\
\text { aplikasi }\end{array}$ \\
\hline Wei, 2019 & $\begin{array}{l}\text { Fasilitas } \\
\text { publik }\end{array}$ & $\begin{array}{c}\mathrm{KE} \\
\text { Evaluation }\end{array}$ & $\begin{array}{l}\text { Fasilitas } \\
\text { public di } \\
\text { Chengdu }\end{array}$ \\
\hline $\begin{array}{l}\text { Ren, Tan, \& } \\
\text { Zhang , } 2019\end{array}$ & $\begin{array}{c}\text { Dasboard } \\
\text { mobil }\end{array}$ & KE & $\begin{array}{c}8 \text { sampel } \\
\text { gambar } \\
\text { dashboard }\end{array}$ \\
\hline Lin Y., 2019 & Visual warna & KESS & Unsur warna \\
\hline
\end{tabular}

Kansei adalah istilah bahasa Jepang yang digunakan untuk mengekspresikan kesan, perasaan dan emosi seseorang terhadap artefak, situasi dan sekitarnya. Berakar dalam pada budaya Jepang, Kansei Engineering memiliki berbagai perbedaan interpretasi dari tiap literatur yang membahas hal ini, Kansei umumnya disebut kepekaan, perasaan dan emosi. Kansei Engineering dijelaskan sebagai teknik yang mengintegrasikan kepekaan, perasaan dan emosi dengan metodologi rekayasa. Tujuannya untuk menganalisis kepekaan, perasaan dan emosi manusia untuk diterjemahkan ke dalam sebuah desain produk (Lokman \& Nagamachi, 2009).

Evaluasi Visual Kansei yang diusulkan peneliti adalah suatu metode evaluasi berdasarkan kalimat atau kata Kansei terhadap konsep elemen desain yang dikuisionerkan ke responden. Elemen-elemen desain yang terpilih digabungkan menjadi satu kesatuan desain komposisi secara utuh. Desain yang terkomposisi secara utuh disurveikan kembali untuk mendapatkan penilaian. Hasil penilaian menjadi data masukan untuk mendesain ulang berdasarkan masukan responden.

\section{Metodologi}

\subsection{Pengumpulan Data}

Data yang digunakan adalah data primer berupa hasil pengamatan dan wawancara responden untuk menggali persepsi positif dan persepsi negatif terhadap sampel terhadap spesimen yang dipilih yaitu los dawet telasih Bu Dermi, los dawet telasih $\mathrm{Bu}$ Siti dan los dawet telasih Hj. Sipon. Sedangkan los lenjongan yang dipilih menjadi sampel adalah los lenjongan Bu Jumiyati, los lenjongan Bu Rubi dan los lenjongan Yu Sum. Data primer lainnya adalah hasil kuisioner responden penelitian terhadap elemen desain kansei. 


\subsection{Tahapan penelitian :}

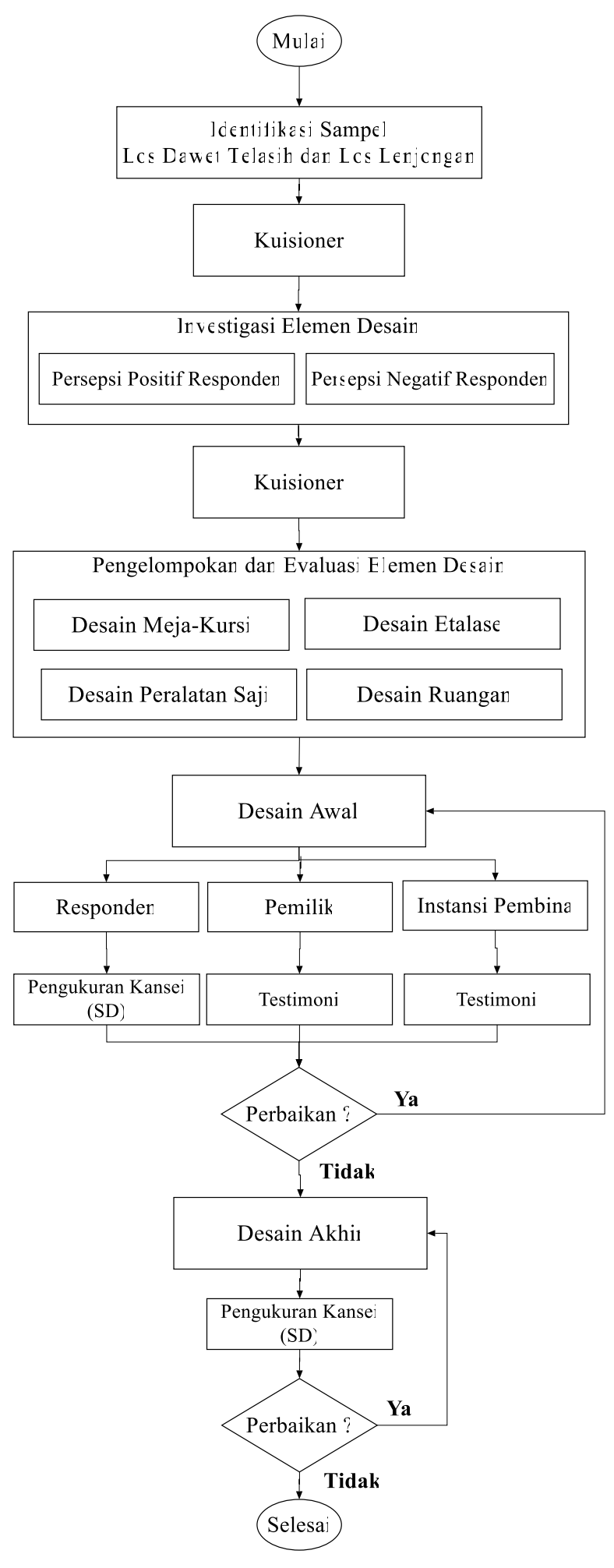

Gambar 2. Tahapan Penelitian

\section{Hasil Dan Pembahasan}

\subsection{Identifikasi Sampel}

Identifikasi terhadap sampel penelitian dilakukan dengan cara pengambilan foto dan video saat aktifitas berjualan langsung pada sampel los dawet telasih dan los lenjongan.

\subsection{Investigasi Elemen Desain}

Investigasi elemen desain dilakukan dengan cara penyebaran kuisioner kepada responden untuk mengetahui persepsi visual kansei terhadap foto dan video situasi pada obyek penelitian. Maksud dari kuisioner untuk mendapatkan penilaian positif dan penilaian negatif responden terhadap aktifitas yang melibatkan elemen desain los.

\subsection{Pengelompokan dan Evaluasi Elemen Desain}

Elemen desain merupakan elemen yang muncul dari pendapat responden terhadap gambar situasi pada lingkungan sampel. Kalimat yang muncul dari ekspresi responden yang memiliki makna yang beragam selanjutnya dikelompokan ke dalam makna kalimat yang memiliki arti sejenis terhadap elemen desain. Peneliti selanjutnya mengusulkan elemen - elemen desain los dawet telasih dan los lenjongan seperti dijelaskan dalam Tabel. 2.

Tabel 2. Elemen Desain Kansei

\begin{tabular}{cc}
\hline No & Elemen Desain \\
\hline 1 & Desain Meja Dan Kursi \\
2 & Desain Etalase \\
3 & Desain Peralatan Saji \\
4 & Desain Ruang \\
\hline
\end{tabular}

Deskripsi elemen desain hasil kuisioner : 3.3.1 Los Dawet Telasih :

Desain Meja Dan Kursi, dengan kriteria : bersih, nyaman, longgar, tidak terlalu lebar, dapat berbincang dengan penjual, kursi ukuran tinggi selaras dengan meja, sederhana, praktis.

Desain Etalase, dengan kriteria : bersih, memadai, dapat dilihat dengan jelas, jernih/ bening penutupnya, tinggi etalase ideal, penataan rapi. 
Desain Peralatan Saji, dengan kriteria : wadah dagangan bersih, mangkuk yang bersih, tampilan wadah atau mangkuk yang unik, menarik dan tradisional.

Desain Ruang, dengan kriteria : tempat terang (cukup cahaya), bersih, lapang/ longgar, akses jalan sekitar longgar, tidak dekat dengan dagangan berbau tajam, lingkungan sekitar bersih, ada pencahayaan untuk display produk, ada papan nama, ada papan menu dan harga.

\subsubsection{Los Lenjongan:}

Desain Meja Dan Kursi, dengan kriteria : bersih, nyaman, longgar, tidak terlalu lebar, dapat berbincang dengan penjual, ukuran tinggi kursi selaras dengan meja, sederhana, nyaman, praktis.

Desain Etalase, dengan kriteria : bersih, memadai, dapat dilihat dengan jelas, jernih/ bening penutupnya, tinggi etalase ideal, penataan rapi, alas dagangan dari bahan alam (daun).

Desain Peralatan Saji, dengan kriteria : wadah dagangan bersih, tampilan wadah unik, menarik dan tradisional.

Desain Ruang, dengan kriteria : tempat terang (cukup cahaya), bersih, lapang/ longgar, akses jalan sekitar longgar, tidak dekat dengan dagangan berbau tajam, lingkungan sekitar bersih, ada pencahayaan untuk display produk, ada papan nama, ada papan menu dan harga.

\subsection{Konsep Desain Awal Los Dawet Telasih}

Elemen desain sketsa los dawet telasih yang terpilih disatukan dan digambarkan secara visual tiga dimensi seperti pada Gambar 3.

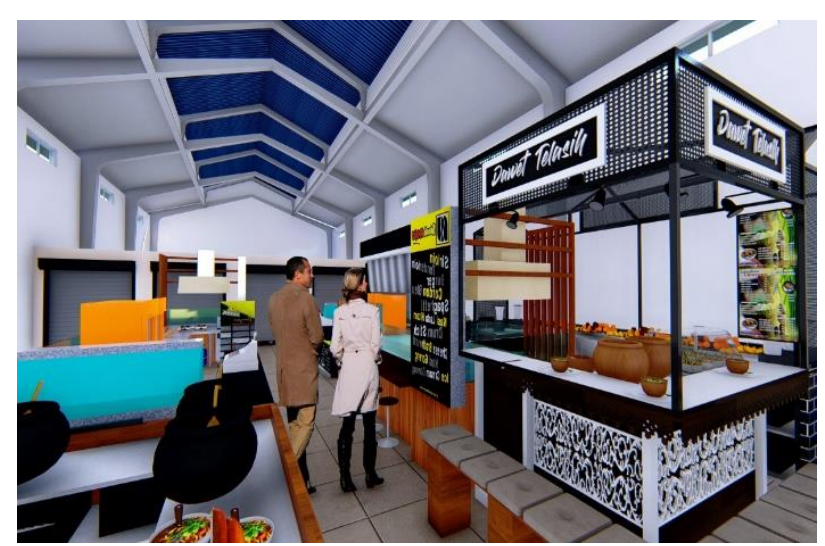

Gambar 3. Desain Awal Los Dawet Telasih

Deskripsi visual elemen desain los dawet telasih pada Gambar 3. selanjutnya akan dijelaskan secara rinci dalam Tabel 3. :

Tabel 3. Elemen Desain Los Dawet Telasih

\begin{tabular}{ll}
\hline Elemen Desain & \multicolumn{2}{c}{ Gambaran Visual Elemen } \\
\hline Desain Meja & Meja : berbahan kayu \\
Dan Kursi & terintegrasi praktis dengan \\
& meja display, ukuran sekitar \\
& panjang lengan orang dewasa, \\
& corak warna natural, relief \\
& batik.
\end{tabular}

Kursi : bahan kayu, bentuk bangku panjang, warna natural, model sederhana dan praktis.

Desain Etalase Bahan kaca bening transparan, bentuk lengkung seperempat lingkaran dan berpenutup.

Desain Peralatan Wadah dagangan dawet : bahan Saji gerabah tanah liat seperti gentong lengkap dengan penutup (untuk kuah dan santan); untuk wadah toping menggunakan gerabah tanah liat berbentuk mangkuk besar. Wadah sajian : mangkuk gerabah atau mangkuk dawet keramik lawas.

Desain Ruang Ruangan bersih dan jauh dari dagangan berbau tdk sedap, memiliki penerangan yang cukup, ada informasi menu dan harga, kombinasi interior jawa, selasar longgar dan bersih. 


\subsection{Desain Awal Los Lenjongan}

Desain awal los lenjongan, merupakan gambaran desain awal dari gabungan sketsa elemen desain los lenjongan.

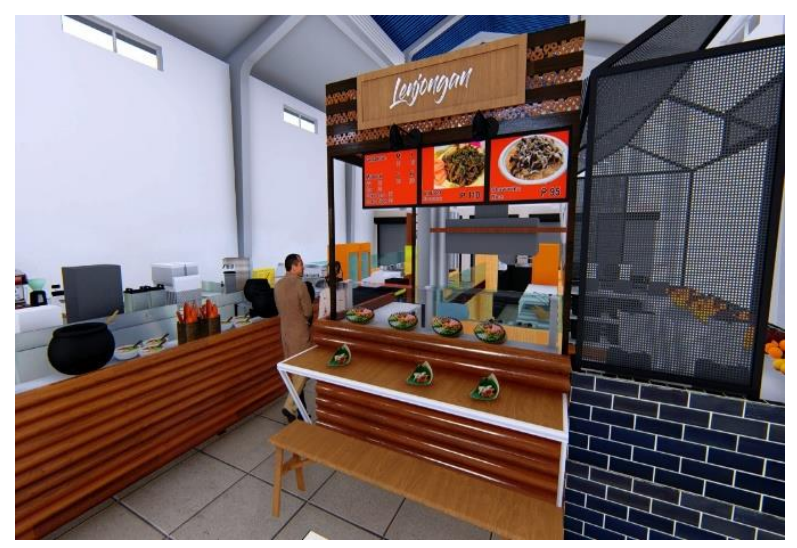

Gambar 4. Desain Awal Los Dawet Telasih

Deskripsi visual elemen desain awal los lenjongan pada Gambar 4. akan dijelaskan secara rinci dalam Tabel 4.

Tabel 4. Desain Awal Los Lenjongan

\begin{tabular}{|c|c|}
\hline Elemen Desain & Gambaran Visual Elemen \\
\hline $\begin{array}{l}\text { Desain Meja Dan } \\
\text { Kursi }\end{array}$ & $\begin{array}{l}\text { Meja : berbahan kayu } \\
\text { terintegrasi praktis dengan meja } \\
\text { display, ukuran sekitar panjang } \\
\text { lengan orang dewasa, corak } \\
\text { warna coklat kayu, relief seni } \\
\text { kayu. } \\
\text { Kursi : bahan kayu, bentuk } \\
\text { tunggal praktis, warna natural. }\end{array}$ \\
\hline Desain Etalase & $\begin{array}{l}\text { Bahan kaca bening transparan, } \\
\text { berpenutup, posisi tepat di } \\
\text { hadapan pembeli. }\end{array}$ \\
\hline $\begin{array}{l}\text { Desain } \\
\text { Saji }\end{array}$ & $\begin{array}{l}\text { Wadah dagangan lenjongan : } \\
\text { bahan anyaman bambu beralas } \\
\text { daun pisang. } \\
\text { Wadah sajian : anyaman bambu } \\
\text { atau anyaman lidi beralas daun } \\
\text { pisang. }\end{array}$ \\
\hline Desain Ruang & $\begin{array}{l}\text { Ruangan bersih dan jauh dari } \\
\text { dagangan berbau tdk sedap, } \\
\text { memiliki penerangan yang } \\
\text { cukup, ada informasi menu dan } \\
\text { harga, kombinasi interior jawa, } \\
\text { selasar longgar dan bersih. }\end{array}$ \\
\hline
\end{tabular}

\subsection{Kata Kansei}

Kata Kansei konsumen terhadap desain awal los dawet telasih dan los lenjongan seperti digambaran dalam Tabel 4.
Tabel 5. Kata Kansei Dalam Kuisioner

\begin{tabular}{ll}
\hline \multicolumn{1}{c}{$\begin{array}{c}\text { Elemen } \\
\text { Desain }\end{array}$} & \multicolumn{1}{c}{ Kata Kansei } \\
\hline $\begin{array}{l}\text { Desain Meja } \\
\text { Dan Kursi }\end{array}$ & $\begin{array}{l}\text { Bersih, unik, tradisional, } \\
\text { nyaman, sederhana, longgar, } \\
\text { menarik }\end{array}$ \\
\hline Desain Etalase & $\begin{array}{l}\text { Bersih, transparan, menarik, } \\
\text { praktis }\end{array}$ \\
\hline Desain & $\begin{array}{l}\text { Bersih, unik, tradisional, } \\
\text { menarik }\end{array}$ \\
\hline Peralatan Saji & $\begin{array}{l}\text { Bersih,terang, tidak bau, } \\
\text { longgar, nyaman, informatif }\end{array}$ \\
\hline
\end{tabular}

\subsection{Pengukuran Kansei Desain Awal}

Pengukuran Kansei terhadap elemen desain los dawet telasih menggunakan pengukuran Semantic Differential dengan interval nilai 1 sampai dengan 5 skala.

Tabel 6. Pengukuran Elemen Desain Los Dawet Telasih

\begin{tabular}{cll}
\hline $\begin{array}{c}\text { Elemen } \\
\text { desain }\end{array}$ & Kata Kansei & $\begin{array}{c}\text { Rata- } \\
\text { rata }\end{array}$ \\
\hline Desain Meja & Bersih & 4.63 \\
Dan Kursi & Unik & 4.31 \\
& Tradisional & 3.69 \\
& Nyaman & 4.38 \\
& Sederhana & 4.00 \\
& Longgar & 4.20 \\
& Menarik & 4.56 \\
\hline & Rata-rata skor & $\mathbf{4 . 1 9}$ \\
\hline Desain Etalase & Bersih & 4.56 \\
& Transparan & 4.00 \\
& Menarik & 4.31 \\
& Praktis & 4.31 \\
\hline Desain & Rata-rata skor & $\mathbf{4 . 3 0}$ \\
\hline Peralatan Saji & Bersih & 4.50 \\
& Unik & 4.44 \\
& Tradisional & 4.25 \\
& Menarik & 3.88 \\
\hline & Rata-rata skor & $\mathbf{4 . 2 7}$ \\
\hline Desain Ruang & Bersih & 4.63 \\
& Terang & 4.50 \\
& Tidak bau & 4.38 \\
& Nyaman & 4.31 \\
& Longgar & 4.25 \\
& Informatif & 4.44 \\
\hline & Rata-rata skor & $\mathbf{4 . 4 2}$ \\
\hline & &
\end{tabular}


Tabel 7. Pengukuran Elemen Desain Kansei Los Lenjongan

\begin{tabular}{|c|c|c|}
\hline Elemen desain & Kata Kansei & $\begin{array}{l}\text { Rata- } \\
\text { rata }\end{array}$ \\
\hline Desain Meja Dan & Bersih & 4.25 \\
\hline \multirow[t]{7}{*}{ Kursi } & Unik & 4.00 \\
\hline & Tradisional & 3.50 \\
\hline & Nyaman & 3.88 \\
\hline & Sederhana & 3.94 \\
\hline & Longgar & 3.93 \\
\hline & Menarik & 4.44 \\
\hline & Rata-rata skor & 3.99 \\
\hline \multirow[t]{5}{*}{ Desain Etalase } & Bersih & 4.25 \\
\hline & Transparan & 4.06 \\
\hline & Menarik & 4.13 \\
\hline & Praktis & 4.25 \\
\hline & Rata-rata skor & 4.17 \\
\hline Desain Peralatan & Bersih & 4.31 \\
\hline \multirow[t]{4}{*}{ Saji } & Unik & 4.13 \\
\hline & Tradisional & 3.63 \\
\hline & Menarik & 4.06 \\
\hline & Rata-rata skor & 4.03 \\
\hline \multirow[t]{7}{*}{ Desain Ruang } & Bersih & 4.25 \\
\hline & Terang & 4.25 \\
\hline & Tidak bau & 4.19 \\
\hline & Nyaman & 3.81 \\
\hline & Longgar & 3.50 \\
\hline & Informatif & 3.94 \\
\hline & Rata-rata skor & 3.99 \\
\hline
\end{tabular}

\subsection{Testimoni Instansi Pembina}

Dinas Perdagangan Kota Surakarta :

Los dawet telasih : "Desain di atas sudah sesuai regulasi/ aturan yang ada, karena pada dasarnya konsep tersebut dapat menambah daya tarik pembeli untuk minimal mengunjungi tempat tersebut. Sesuai regulasi menambah atau mengurangi bentuk los harus seizin Dinas Perdagangan, namun konsep di atas secara khusus dapat diperbolehkan. Desain di atas warnanya kurang menarik perlu ditambah warna yang sesuai dengan dawet telasih."

Los Lenjongan : "Konsep los lenjongan di atas bagus dan menarik untuk dikunjungi oleh calon pembeli. Secara aturan dan regulasi konsep desain los di atas tidak menyalahi aturan. Space untuk pembeli yang mau makan di tempat kurang leluasa seharusnya ada areal tempat makan yang khusus dan nyaman”

\subsection{Testimoni Pelaku Usaha}

Los dawet telasih : "Warna dan motif kurang cerah, ruang gerak penjual dan pegawainya kurang, pintu keluar masuknya kalau bisa dua pintu, sudah lumayan bagus praktis, tulisan kurang mencolok/ kurang jelas". "Desain minimnalis bagus untuk dawet telasih, terlihat mewah dan besar, tapi apakah bisa ditrapkan dipasar besar yang beraneka jualan yang disajikan, semoga ideide yang positif bisa menaikkan martabat kota Surakarta yang ramah, semoga ide yang bagus tidak memberatkan masyarakat, Maju terus Kota Surakarta yang berseri”. "Cukup bagus,tempat di depan kurang panjang, penataan tempat sudah bagus"

Los Lenjongan: "Sudah bagus, cocok". "Sangat bagus dan terlihat bersih dan luas akan sangat bagus sekali jika ditempatkan di area khusus makanan dan sangat setuju sekali dikasih seating area sebab banyak wisatawan yang bingung untuk cari tempat duduk, jika makan sambil jalan atau berdiri sangat tidak njawani dan kurang sopan". "Sangat bagus dan terlihat bersih, luas, sangat nyaman dan tidak umpek-umpekan, jika tempatnya luas saya sangat setuju jika kuliner ada seting areanya sangat nyaman untuk makan dan duduk menikmati tidak bersenggolan dengan kuli-kuli angkut buah"

Desain akhir los dawet telasih dilakukan penyesuaian setelah mendapatkan masukan dari pemangku kepentingan yang terlibat dalam pengelolaan los dawet telasih yaitu Dinas Perdagangan dan pelaku usaha itu sendiri. Penyesuaian yang dilakukan adalah warna tiang dan tampilan nama los yang lebih cerah dan menyesuaikan unsur warna dari dawet telasih. Konsep desainnya seperti Gambar 5.

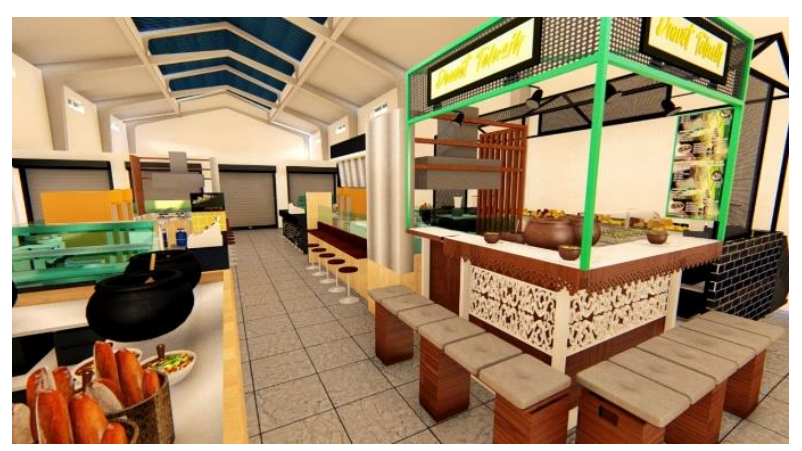

Gambar 5. Desain Akhir Los Dawet Telasih 
Untuk desain akhir los lenjongan tidak dilakukan penyesuaian karena desain awal di pandang sudah memenuhi harapan dari konsumen, instansi pembina dan pelaku usaha.

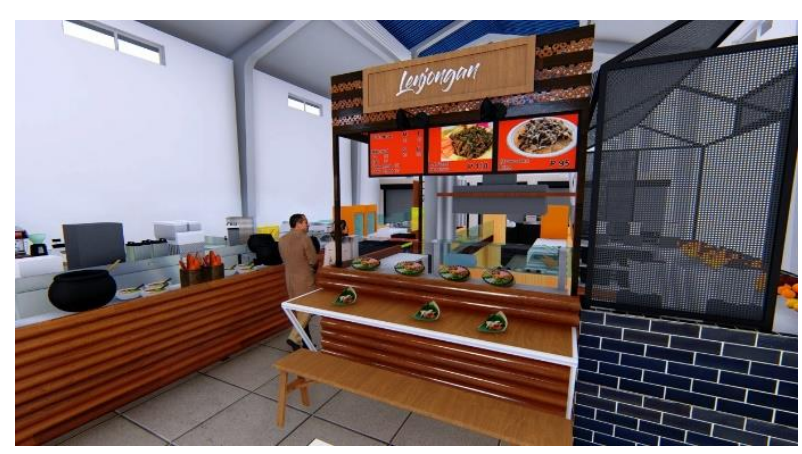

Gambar 6. Desain Akhir Los Lenjongan

\subsection{Pengukuran Kansei Desain Akhir}

Pengukuran Kansei desain akhir los dawet seperti digambarkan dalam Tabel 8 .

Tabel 8. Pengukuran Kansei Desain Akhir Los Dawet Telasih

\begin{tabular}{|c|c|c|}
\hline Elemen desain & Kata Kansei & $\begin{array}{c}\text { Rata- } \\
\text { rata }\end{array}$ \\
\hline \multirow{7}{*}{ Desain Meja Dan Kursi } & Bersih & 4,30 \\
\hline & Unik & 4,30 \\
\hline & Tradisional & 3,60 \\
\hline & Nyaman & 4,25 \\
\hline & Sederhana & 4,10 \\
\hline & Longgar & 3,70 \\
\hline & Menarik & 4,00 \\
\hline & Rata-rata skor & 4,04 \\
\hline \multirow{5}{*}{ Desain Etalase } & Bersih & 4,30 \\
\hline & Transparan & 4,30 \\
\hline & Menarik & 4,10 \\
\hline & Praktis & 4,00 \\
\hline & Rata-rata skor & 4,18 \\
\hline \multirow{12}{*}{ Desain Peralatan Saji } & Bersih & 4,30 \\
\hline & Unik & 4,40 \\
\hline & Tradisional & 4,20 \\
\hline & Menarik & 4,15 \\
\hline & Rata-rata skor & 4,26 \\
\hline & Bersih & 4,20 \\
\hline & Terang & 4,35 \\
\hline & Tidak bau & 4,20 \\
\hline & Nyaman & 4,40 \\
\hline & Longgar & 4,25 \\
\hline & Informatif & 4,10 \\
\hline & Rata-rata skor & 4,25 \\
\hline
\end{tabular}

Tabel 8. menunjukkan bahwa nilai rata-rata elemen desain meja kursi 4,04, elemen desain etalase 4,18 , elemen desain peralatan saji 4,26 dan elemen desain ruang 4,25 menunjukkan bahwa desain pada Gambar
5. disukai atau dipandang menarik oleh responden.

Tabel 9. Pengukuran Kansei Desain Akhir Los Lenjongan

\begin{tabular}{clc}
\hline Elemen desain & Kata Kansei & $\begin{array}{c}\text { Rata- } \\
\text { rata }\end{array}$ \\
\hline \multirow{4}{*}{ Desain Meja Dan Kursi } & Bersih & 4,40 \\
& Unik & 4,10 \\
& Tradisional & 4,05 \\
& Nyaman & 4,20 \\
& Sederhana & 3,90 \\
& Longgar & 3,85 \\
& Menarik & 4,20 \\
\hline & Rata-rata skor & $\mathbf{4 , 1 0}$ \\
\hline & Bersih & 4,30 \\
Desain Etalase & Transparan & 4,30 \\
& Menarik & 4,25 \\
& Praktis & 4,25 \\
\hline & Rata-rata skor & $\mathbf{4 , 2 8}$ \\
\hline & Bersih & 4,10 \\
Desain Peralatan Saji & Unik & 4,10 \\
& Tradisional & 4,30 \\
& Menarik & 4,10 \\
\hline & Rata-rata skor & $\mathbf{4 , 1 5}$ \\
\hline & Bersih & 4,35 \\
& Terang & 4,00 \\
& Tidak bau & 4,20 \\
& Nyaman & 4,25 \\
& Longgar & 3,80 \\
& Informatif & 4,10 \\
\hline & Rata-rata skor & $\mathbf{4 , 1 2}$ \\
\hline & &
\end{tabular}

Tabel 9. menunjukkan bahwa nilai rata-rata elemen desain meja kursi 4,10, elemen desain etalase 4,28, elemen desain peralatan saji 4,15 dan elemen desain ruang 4,12 menunjukkan bahwa desain pada Gambar 6. juga disukai atau dipandang menarik oleh responden.

\section{Kesimpulan}

Metode Evaluasi Visual Kansei berhasil diterapkan dalam perancangan desain los dawet telasih dan los lenjongan yang menarik secara visual. Persepsi negatif responden terhadap desain yang ada saat ini dapat terjawab dengan konsep desain yang ditawarkan dalam penelitian ini. Untuk penelitian selanjutnya disarankan mengkaji hal-hal yang dapat meningkatkan minat berkunjung ke Pasar Gede dari sisi harga barang, kualitas barang, kualitas pelayanan dan atmosfer pasar. 


\section{Daftar Pustaka}

Arsovski, S., Rackov, M., \& Ivanovic, L. (2017). Emotional Design and Quality of life. June, 87-94.

CHENG, B., LIN, L., \& YANG, M.-Q. (2017). The Analytical Method of Product Multidimensionality Form Elements for Kansei Engineering. DEStech Transactions on Engineering and Technology Research, $m d m$.

https://doi.org/10.12783/dtetr/mdm2016/ 4942

Haddadian, M. (2016). Visual Assessment of Methods of Street Furniture Installation Using Kansei Engineering (Case Study: Benches in the Historical-Cultural Area of Tabriz). Modern Applied Science, 10(6), https://doi.org/10.5539/mas.v10n6p171

Hadiana, A., Permana, B., \& Tjahjadi, D. (2019). Kansei Approach in Development of Application Interface Design Based on User's Emotional Feeling. European Journal of Engineering Research and Science, 4(10), 121-126. https://doi.org/10.24018/ejers.2019.4.10. 1566

Hapsari, S. N., Sjafrizal, T., \& Anugraha, R. A. (2017). Designing Train Passenger Seat by Kansei Engineering in Indonesia. MATEC Web of Conferences, 135. https://doi.org/10.1051/matecconf/20171 3500017

Hsiao, Y. H., \& Chen, G. T. (2018). Customer Kansei-oriented restaurant location evaluation using Kansei Engineering. 2018 5th International Conference on Industrial Engineering and Applications, ICIEA 2018, 299-303. https://doi.org/10.1109/IEA.2018.83871 14

Kagitani, K., Deng, P., Matsuda, E., Aizaki, T., Nakamura, S., Suzuki, T., Tachikawa, M., Aoki, N., \& Kobayashi, H. (2015). Toward Image Emotion Space: Evaluation of Image Impression Shifts with Kansei Words. Bulletin of the Society of Photography and Imaging of Japan, 25(1), 19-24. http://www.spstj.org/item/pdf/14519984 28_tayori_pdf.pdf

Kobayashi, M., Kinumura, T., \& Higashi, M. (2019). A Method for Supporting Aesthetic Design based on the Analysis of the Relationships between Customer Kansei and Aesthetic Element. 71-74. https://doi.org/10.14733/cadconfp.2015. 71-74

Kurochka, S., Sviruk, L., Kuleshova, S., \& Zakharkevich, O. (2017). Method of analyzing images of clothes based on kansei engineering. Applied Researches in Technics, Technologies and Education, 5(3), 182-189. https://doi.org/10.15547/artte.2017.03.0 05

Lin, C. C., Tsai, W. H., \& Yu, S. J. (2017). Kaohsiung image oriented product design based on Kansei Form Composition approach. Proceedings of the 2017 IEEE International Conference on Applied System Innovation: Applied System Innovation for Modern Technology, ICASI 2017, 1539-1542. https://doi.org/10.1109/ICASI.2017.798 8220

Lin, Y.-H., Pan, H.-Y., \& Lin, J.-Y. (2017). Applying Taiwan Aboriginal culture's feature to product Design. 131(Icoi), 223-226. https://doi.org/10.2991/icoi17.2017 .50

Lin, Y. (2019). Research on Visual Color Matching Based on Kansei Engineering. 356(Cesses), 556-562. https://doi.org/10.2991/cesses19.2019.126

LOKMAN, A. M., \& NAGAMACHI, M. (2009). Validation of Kansei Engineering Adoption in E-commerce Web Design. Kansei Engineering International Journal, 9(1), 21-27. https://doi.org/10.5057/kei.9.21

Mamaghani, N. K., \& Mostowfi, S. (2016). Kansei Engineering and environmental design. International Journal of Environmental Sciences, 6(5), 758-765. https://doi.org/10.6088/ijes.6071

Quan, H., Li, S., \& Hu, J. (2018). Product innovation design based on deep learning and Kansei engineering. Applied 
Sciences (Switzerland), 8(12), 1-17. https://doi.org/10.3390/app8122397

Ramachandiran, C. R., \& Jomhari, N. (2015). A case study on e-learners perception and kansei experience towards pedagogical virtual agents. Indian Journal of Science and Technology, 8(11). https://doi.org/10.17485/ijst/2015/v8i11/ 71792

Ren, H., Tan, Y., \& Zhang, N. (2019). Research on Form Design of Automotive Dashboard Based on Kansei Engineering. IOP Conference Series: Materials Science and Engineering, 573(1). https://doi.org/10.1088/1757899X/573/1/012090

Rosen, B. G., Eriksson, L., \& Bergman, M. (2016). Kansei, surfaces and perception engineering. Surface Topography: Metrology and Properties, 4(3). https://doi.org/10.1088/2051$672 \mathrm{X} / 4 / 3 / 033001$

Shaari, N. (2016). Kansei: The Creative Mind In theVisual Analyzing Process. Archives of Design Research, 29(1), 19. https://doi.org/10.15187/adr.2016.02.29. 1.19

Shao, D., Nagai, Y., \& Sosa, R. (2019). Design for Sustainability and Innovation: A Kansei Engineering Evaluation of the Adaptive Reuse of Old Buildings. Proceedings of the Design Society: International Conference on Engineering Design, 1(1), 3221-3230. https://doi.org/10.1017/dsi.2019.329

Soikun, T. M., Asri, A., \& Ibrahim, A. (2019). Achieving 'appeal' through kansei approach. 1995.

Sulistyaningtyas, T., Jaelani, J., \& Waskita, D. (2012). Bandung Akibat Pengaruh Gaya Hidup Digital. Jurnal Sosioteknologi, Edisi 27(11), 157-168.

Urquhart, L. W. R., \& Wodehouse, A. (2017). The emotive qualities of patterns: Insights for design. Proceedings of the International Conference on Engineering Design, ICED, 8(DS87-8), 109-118.

Wang, M. F., \& Hsiao, S. W. (2018). A Kansei-oriented Method for Interior Design. Proceedings of the 2018 IEEE 22nd International Conference on Computer Supported Cooperative Work in Design, CSCWD 2018, 50-56. https://doi.org/10.1109/CSCWD.2018.8 465186

Wang, W., Liu, Y., Karim, M. S. B. A., \& Amran, N. A. binti M. (2017). Visual Related Analysis and Application of Saline Soil Culture Design Factors. International Journal of Multimedia and Ubiquitous Engineering, 12(8), 43-54. https://doi.org/10.14257/ijmue.2017.12. 8.05

Wei, X. (2019). Research of Human Culture Design of City Public Environment Facilities Based on Kansei Engineering With Chengdu as Example. IOP Conference Series: Earth and Environmental Science, 242(5). https://doi.org/10.1088/17551315/242/5/052016

Xiong, Z., Liu, M., Weng, Y., \& Liu, Y. (2018). Research of Customer Product Form Preference based on Kansei Engineering. Journal of Physics: Conference Series, 1087(6). https://doi.org/10.1088/17426596/1087/6/062051

Yoshida, T., Maekawa, M., KEER2018, Y. T.-, with, G. G., \& 2018, undefined. (2018). Specifying Kansei Requirements with the Application of Environmental Psychology Research Methods. Ep.Liu.Se, 379-389. http://www.ep.liu.se/ecp/article.asp?issu $\mathrm{e}=146 \&$ article $=041 \&$ volume $=$ 